\title{
Effects of laser therapy and Grimaldi's muscle shortening manoeuvre on motor control of subjects with incomplete spinal cord injuries
}

\author{
Diego Longo ${ }^{1}$, Leonardo Longo ${ }^{1}$, Paolo Lippi ${ }^{2}$, Giulio Cherubini ${ }^{1}$,Vanessa Mangé ${ }^{1}$ \\ 1: Institute Laser Medicine, International Academy Laser Medicine And Surgery, Florence, Italy \\ 2: University of Florence, Florence, Italy
}

\begin{abstract}
Background and Objectives: From year 2003 we treated positively 251 patients with Traumatic Spinal Cord Injuries (TSCI), using Non-Surgical Laser Therapy (NSLT). In order to increase muscle strength, we have also started using a physical therapy practice called Grimaldi's Muscle Shortening Manoeuvre (GMSM)

The goal of our study is to obtain objective data suggesting the real effectiveness of the association of these two treatments.

Study Design and Methods: In 2015, 10 patients with incomplete TSCI were enrolled. Further 10 subjects with similar features were included as control group. All patients have subtotal sensory loss and motor paralysis below the level of the lesion. Lasers used were 808, 10600, and $1064 \mathrm{~nm}$, applied with a first cycle of four sessions per day for a total of 20 sessions. The patients participated in specific physical therapy training (GMSM) twice a day, for a total of eight sessions.

Each cycle of laser and GMSM was replicated each month.

Results: Results were considered positive if sensitivity increased at least two dermatomes per cycle under the level of the lesion. Results in muscle activity (on/off) were regarded as positive if sEMG showed modifications in CNS-muscle. Objective assessment of force displayed encouraging results. After each cycle, patients showed improvements in motor function and voluntary command. Follow-up is positive after 3 months.

Conclusion: Associating laser treatment and Grimaldi's Muscle Shortening Manoeuvre (MSM) seems to be effective on muscle strength and motor control in patients affected by subtotal SCI compared to a control group
\end{abstract}

Key words: Laser Therapy of Spinal Cord Traumatic Lesions • Grimaldi Manoeuvre • laser therapy of muscle shortering $\cdot$ laser motor control $\cdot$ laser biomodulation . laser antinflammatory $\cdot$ laser muscle tone $\cdot$ laser nerve regeneration

\section{Introduction}

From December 2003 until June 2016 we treated 251 patients with Traumatic Spinal Cord Injuries (TSCI), using Non-Surgical Laser Therapy (NSLT) 1) obtaining good results in terms of sensitivity and movement ${ }^{2}$. To increase muscle strength and to further explore new emerging synergies, we have also started using a

\section{Addressee for Correspondence:}

Diego Longo, PT,

Institute Laser Medicine, International Academy of Laser

Medicine and Surgery

Firenze - Italy

ddlongo@gmail.com;

Tel/Fax 00390552342330 physical therapy practice based on the most current knowledge about motor control ${ }^{3}$, 4), called Grimaldi's Muscle Shortening Manoeuvre (MSM) ${ }^{5)}$.

Each case of TSCI is different, there are not two similar injuries in terms of loss of function and response to treatment.

For this reason, statistical data play a limited role as too many variables are involved at the same time $1,2)$

The goal of our study is to obtain objective data suggesting the real effectiveness of the association of these two treatments.

Received date: May 6th, 2017

Accepted date: June 24th, 2017 


\section{Study Design and Methods}

In 2015, 10 patients with incomplete TSCI - with injuries sustained at least one year before laser treatment and documented by NMR or CT, ESSP, and ESMP - were enrolled (table 1). Selection criteria are shown in table 2. At the same time, another 10 subjects with similar features were included as one control group. Informed consent was obtained from all individual participants included in the study. Before treatment, muscle activity below the level of lesion, was tested with surface EMG (sEMG). Clinical evaluations included determining superficial and deep tactile and thermal sensitivity below the lesion level. International clinical

Table 1

\begin{tabular}{cccccc}
\hline PATIENTS & GROUP & SEX & AGE & INJURY_LEVEL & A.I.S. \\
\hline 1 & A & M & 43 & C5-C6-C7 & B \\
2 & A & M & 38 & C5 & B \\
3 & A & F & 28 & C5-C6-C7 & B \\
4 & A & M & 30 & C5-C6-C7 & B \\
5 & A & M & 27 & C4-C5-C6 & B \\
6 & A & M & 31 & C5-C6-C7 & C \\
7 & A & M & 24 & C4 & B \\
8 & A & M & 54 & C4-C5 & B \\
9 & A & M & 19 & C3 & B \\
10 & A & M & 31 & C5-C6 & B \\
11 & B & F & 36 & C7 & B \\
12 & B & M & 28 & C5-C6 & B \\
13 & B & M & 44 & C6 & B \\
14 & B & M & 22 & C5 & B \\
15 & B & M & 52 & C4 & B \\
16 & B & M & 30 & C3-C4-C5 & B \\
17 & B & F & 41 & C6-C7 & B \\
18 & B & F & 43 & C6-C7 & B -C7 \\
19 & B & M & 34 & 23 & C \\
20 & B & M & & & \\
\hline
\end{tabular}

Table 2

20 Participants (2 groups)

\begin{tabular}{ll}
\hline \multicolumn{1}{c}{ Inclusion Criteria: } & \multicolumn{1}{c}{ Exclusion Criteria: } \\
\hline - C1-C7 (57\% of all SCI) & - Surgical intervention contra-nature \\
- Both sex, $18-40$ years old & - Orthopedic complications (deformity, pain) \\
- SCI occurred at least one year & - Inability to join the program in its entirety (economic, logistic, voluntary, etc) \\
- AIS B, C & \\
\hline
\end{tabular}


evaluation scales, such as ASIA Impairment Scale (AIS) and Ashworth Scale were used for assessments. Prior to starting treatment, muscle strength at specific joints was assessed with electronic dynamometers and goniometers (Jtech Commander Echo) and then before and after each manoeuvre and at the end of each cycle of laser treatment. All patients have subtotal sensory loss and motor paralysis below the level of the lesion. Lasers used were 808 nm (Eufoton, Trieste, Italy) 10600 nm (General Project, Firenze, Italy), and 1064 nm (Aerolase, NY, USA), applied with a first cycle of four sessions per day for a total of 20 sessions (table 3). Different laser wavelengths were used because each wavelength has a different penetration ${ }^{6,7)}$. Details about the dosage are specified in table 3 . One dosage of 720 Joules $/ \mathrm{cm}^{2}$ in total used with laser $808 \mathrm{~nm}$, aimed at achieving an anti-inflammatory effect, according to current knowledge 1, 6, 8, 9, 10). Another dosage of 240 Joules $/ \mathrm{cm}^{2}$ in total was used for regenerative purposes 1, 6, 11, 12), always with the same laser 808 . Lasers of $10600 \mathrm{~nm}$ and $1064 \mathrm{~nm}$ were used at dosages of 36 Joules/scm that could influence muscle tone 13 , $14,15)$. The patients participated in specific physical therapy training (Grimaldi's Muscle Shortening Manoeuvre - GMSM) twice a day, for a total of eight sessions, working selectively on shoulder, elbow and trunk joints and muscles. GMSM is a technique which works on neuromuscular spindles with the aim of producing stimulation. It intentionally balances the short- ening and lengthening of the muscle simultaneously ${ }^{5}$. This process produces an informational catastrophe in the neuromuscular spindles forcing them to set new muscle thresholds. This kind of manoeuvre is an active but involuntary training for the patient.

Each cycle of laser and GMSM treatment was replicated each month. The controls did not receive any kind of treatment but all the variables were assessed as for the treated group.

In statistical analysis we used Fisher-Yates Test to analyse sensitivity and muscle activity (EMG). For evaluating the muscle strenght we compared the results obtained for each parameter in three observation times (T0, T1, T2) for both groups. For this reason, we used Repeated Measures ANOVA, which let us known if there are significant differences between the followups. We chose the Post-Hoc Test (Bonferroni Procedure) to define which difference result significant (T0-T1), (T1-T2), (T0-T2).

\section{Results}

Regarding sensitivity, results were considered positive if sensitivity increased at least two dermatomes per cycle under the level of the lesion. After one month all ten patients in the treatment group showed positive results in surface tactile sensitivity while just one participant did in the control group (p 0.000). After three months, we found eight positive results in the treat-

Table 3

\begin{tabular}{|c|c|c|c|c|}
\hline & $\begin{array}{c}\text { Treatment of } \\
\text { Inflammation and Edema }\end{array}$ & $\begin{array}{l}\text { Support of Nerve } \\
\text { Regeneration }\end{array}$ & Muscle Tone & $\begin{array}{c}\text { Anti-inflammatory } \\
\text { Muscle Tone }\end{array}$ \\
\hline Laser & diode $808 \mathrm{~nm}$ wavelength & diode $808 \mathrm{~nm}$ wavelength & $\begin{array}{l}\mathrm{CO} 210,600 \mathrm{~nm} \\
\text { wavelength }\end{array}$ & $\begin{array}{c}\text { Nd-YAG } 1064 \mathrm{~nm} \\
\text { wavelength }\end{array}$ \\
\hline Output power & $10 \mathrm{~W}$ & $10 \mathrm{~W}$ & $15 \mathrm{~W}$ & $5 \mathrm{~W}$ \\
\hline Spot size & $5 \mathrm{~cm}$ & $5 \mathrm{~cm}$ & $10 \mathrm{~cm}$ & $6 \mathrm{~mm}$ \\
\hline Fluence & $12 \mathrm{~J} / \mathrm{cm}^{2}$ & $4 \mathrm{~J} / \mathrm{cm}^{2}$ & $36 \mathrm{~J} / \mathrm{cm}^{2}$ & $35 \mathrm{~J} / \mathrm{cm}^{2} /$ passage \\
\hline Total Energy & $720 \mathrm{~J}$ & $240 \mathrm{~J}$ & variable & variable \\
\hline Repetition Rate & $1000 \mathrm{HZ}$ & $10 \mathrm{HZ}$ & Continuous Wave & $1 \mathrm{HZ}$ \\
\hline Tissue Target & Spinal Lesion & $\begin{array}{l}\text { Nerve Trigger Points } \\
\text { Coherence Domains }\end{array}$ & Around the lesion & $\begin{array}{c}\text { Area of Lesion and } \\
\text { adjacent tissue }\end{array}$ \\
\hline Sessions per day & 4 & 4 & 4 & 4 \\
\hline $\begin{array}{l}\text { Sessions } \\
\text { per Cycle }\end{array}$ & \multicolumn{4}{|c|}{ First 3 cycles, each of 20 sessions, with interval of 1 month } \\
\hline
\end{tabular}


ment group while none of the control group members showed any results (p 0.001) (tab. 4).

At the first follow up eight patients in the treatment group showed positive results in deep tactile sensitivity while just two in control group did. In this analysis, the Fisher-Yates test did not show any statistical significance (p 0.012). At the second follow up we found nine positive results in the treatment group compared to 0 in the control group (p 0.000) (tab. 5).

Regarding thermal sensitivity, we found 7 positive results at both the follow ups in the treatment group while none were observed in the control group ( $\mathrm{p}$ 0.002) (tab. 6).
Results in muscle activity (on/off) were regarded as positive if sEMG showed modifications in CNS-muscle conduction spikes, under the level of the lesion. After one month, all ten subjects in the treatment group showed positive results while just one in the control group did (p 0.000). After three months 8 participants had still positive results in the treatment group compared to 0 in the control group (p 0.000) (tab. 7). The objective assessment of strength, trunk range of motion and balance displayed encouraging results in the patients assigned to the treatment group.

Muscle strength was assessed in three movements: shoulder flexion, elbow extension and trunk

Table 4

\section{Surface Tactile Sensitivity}

Results have been regarded as positive if sensitivity increases at least of 2 dermatomers/cycle under the level of lesion.

\begin{tabular}{ccccccc}
\hline & & T1 & & \multicolumn{2}{c}{ T2 } \\
\cline { 2 - 7 } & Positive & Negative & Total & Positive & Negative & Total \\
\hline Treatment & 10 & 0 & 10 & 8 & 2 & 10 \\
\hline Control & 1 & 9 & 10 & 0 & 12 & 20 \\
\hline Total & 11 & 9 & 20 & FISHER-YATES TEST: $\mathbf{p} \mathbf{0 . 0 0 1}$ \\
\hline
\end{tabular}

Table 5

\section{Deep Tactile Sensitivity}

Results have been regarded as positive if sensitivity increases at least of 2 dermatomers/cycle under the level of lesion.

\begin{tabular}{ccccccc}
\hline & \multicolumn{1}{c}{ T1 } & \multicolumn{2}{c}{ T2 } \\
\cline { 2 - 6 } & Positive & Negative & Total & Positive & Negative & Total \\
\hline Treatment & 8 & 2 & 10 & 9 & 1 & 10 \\
\hline Control & 2 & 8 & 10 & 0 & 10 & 10 \\
\hline Total & 10 & 10 & FISHER-YATES TEST: $\mathbf{p ~ 0 . 0 0 0}$ \\
\hline
\end{tabular}

Table 6

\section{Thermal Sensitivity}

Results have been regarded as positive if sensitivity increases at least of 2 dermatomers/cycle under the level of lesion.

\section{T1} T2

\begin{tabular}{ccccccc} 
& Positive & Negative & Total & Positive & Negative & Total \\
\hline Treatment & 7 & 3 & 10 & 7 & 3 & 10 \\
\hline Control & 0 & 10 & 10 & 0 & 10 & 10 \\
\hline Total & 7 & 20 & 7 & 13 & 20 \\
\hline \multicolumn{2}{c}{ FISHER-YATES TEST: $\mathbf{p} \mathbf{0 . 0 0 2}$} & \multicolumn{2}{c}{ FISHER-YATES TEST: $\mathbf{p} 0.002$} \\
\hline
\end{tabular}


flexion. Shoulder flexion increased by an average of $24.2 \mathrm{~N}$ in the treatment group at the first follow up and $26.5 \mathrm{~N}$ at the second while an unappreciable increase was noticed in the control group. In this way, after three months we found an increase of $50.7 \mathrm{~N}$ with respect to the baseline (Fig.1) This increase in the treatment group was statistically significant (ANOVA), in addition, the strength change obtained between fol- low-up, (T0-T1) (T1-T2) (T0-T2) are statistically significant (Post-Hoc Test) (tab.8)

Elbow extension increased by an average of 21.7 $\mathrm{N}$ in the treatment group at the first follow up and 16.1 $\mathrm{N}$ at the second while no appreciable increase was noticed in the control group. In this way, after three months we found an increase of $37.8 \mathrm{~N}$ with respect to the baseline (Fig.2) This increase in the treatment

Table 7

\section{Muscle Activity (on/off)}

Results have been regarded as positive if sEMG shows activity at least in two muscles under the level of lesion

\begin{tabular}{ccccccc}
\hline & \multicolumn{1}{c}{ T1 } & \multicolumn{2}{c}{ T2 } \\
\cline { 2 - 7 } & Positive & Negative & Total & Positive & Negative & Total \\
\hline Treatment & 10 & 0 & 10 & 8 & 2 & 10 \\
\hline Control & 1 & 9 & 10 & 0 & 12 & 20 \\
\hline Total & 11 & 9 & FISHER-YATES TEST: $\mathbf{p} \mathbf{0 . 0 0 0}$ \\
\hline
\end{tabular}

Table 8

\section{SHOULDER FLEXION}

\begin{tabular}{|c|c|c|c|c|}
\hline & & T0 & $\mathrm{T} 1$ & $\mathrm{~T} 2$ \\
\hline \multirow{5}{*}{$\begin{array}{l}\text { TREATMENT } \\
\text { GROUP }\end{array}$} & AVERAGE & 70,80 & 95,00 & 121,50 \\
\hline & STANDARD DEVIATION & 50,453 & 53,143 & 62,426 \\
\hline & STANDARD ERROR & 15,955 & 16,805 & 19,741 \\
\hline & ANOVA & & 0,000 & \\
\hline & POST HOC & T0-T1 0,025 & T1-T2 0,006 & Т0-Т2 $\mathbf{0 , 0 0 1}$ \\
\hline \multirow{5}{*}{ CONTROL GROUP } & AVERAGE & 90,10 & 93,20 & 90,60 \\
\hline & STANDARD DEVIATION & 38,010 & 43,091 & 43,066 \\
\hline & STANDARD ERROR & 12,020 & 13,627 & 13,619 \\
\hline & ANOVA & & 0,657 & \\
\hline & POST HOC & T0-T1 -.--- & T1-T2 -.--- & T0-T2 -.-- \\
\hline
\end{tabular}

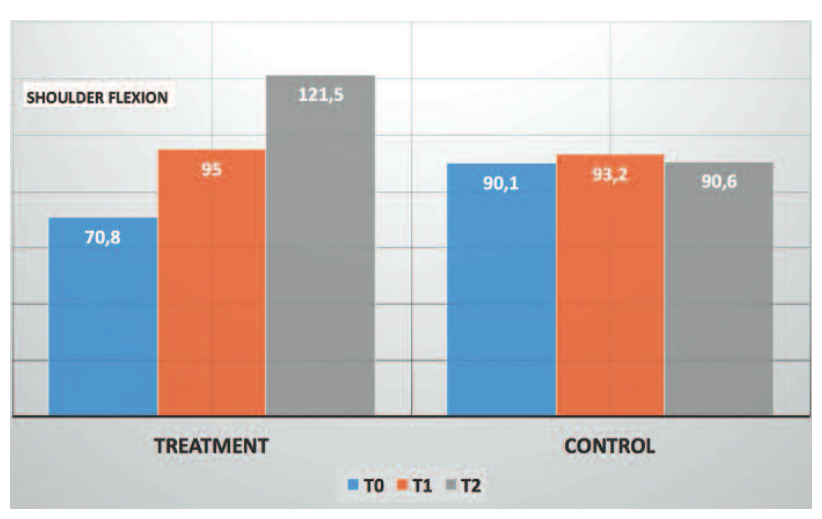

Fig. 1

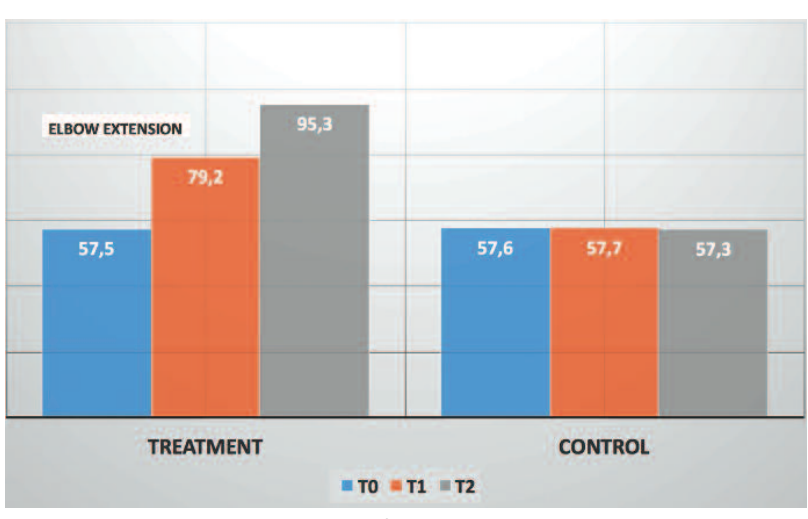

Fig. 2 
group was statistically significant (ANOVA), in addition, the strength change obtained between follow-up, (T1-T2) (T0-T2) are statistically significant (Post-Hoc Test) (tab.9).

Trunk flexion increased by an average of $30.2 \mathrm{~N}$ in the treatment group at the first follow up and $26.5 \mathrm{~N}$ at the second while no appreciable increase was noticed in the control group. In this way, after three months we found an increase of $56.7 \mathrm{~N}$ with respect to the baseline (Fig.3) This increase in the treatment group was statistically significant (ANOVA), in addition, the strength change obtained between follow-up, (T0-T1) (T1-T2) (T0-T2) are statistically significant

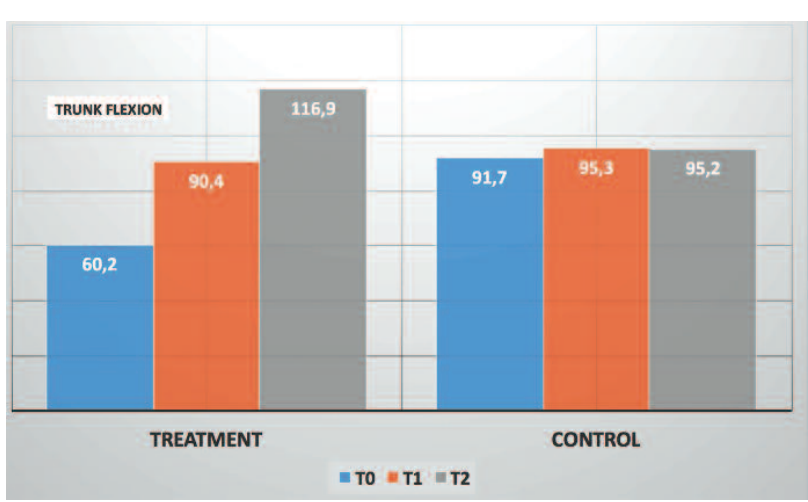

Fig. 3 (Post-Hoc Test) (tab.10).

The control group showed some minor improve-

Table 9

\section{ELBOW EXTENSION}

\begin{tabular}{|c|c|c|c|c|}
\hline & & T0 & $\mathrm{T} 1$ & $\mathrm{~T} 2$ \\
\hline \multirow{5}{*}{$\begin{array}{l}\text { TREATMENT } \\
\text { GROUP }\end{array}$} & AVERAGE & 57,50 & 79,20 & 95,30 \\
\hline & STANDARD DEVIATION & 47,263 & 68,195 & 63,610 \\
\hline & STANDARD ERROR & 14,946 & 21,565 & 20,115 \\
\hline & ANOVA & & 0,000 & \\
\hline & POST HOC & T0-T1 $\mathbf{0 , 0 8 4}$ & T1-T2 $\mathbf{0 , 0 2 8}$ & T0-T2 0,003 \\
\hline \multirow{5}{*}{ CONTROL GROUP } & AVERAGE & 57,60 & 57,70 & 57,30 \\
\hline & STANDARD DEVIATION & 36,265 & 36,022 & 38,480 \\
\hline & STANDARD ERROR & 11,468 & 11,391 & 12,168 \\
\hline & ANOVA & & 0,987 & \\
\hline & POST HOC & T0-T1 -.--- & T1-T2 ---- & T0-T2 --.-- \\
\hline
\end{tabular}

Table 10

TRUNK FLEXION

\begin{tabular}{|c|c|c|c|c|}
\hline & & T0 & $\mathrm{T} 1$ & $\mathrm{~T} 2$ \\
\hline \multirow{5}{*}{$\begin{array}{l}\text { TREATMENT } \\
\text { GROUP }\end{array}$} & AVERAGE & 60,20 & 90,40 & 116,90 \\
\hline & STANDARD DEVIATION & 48,689 & 60,519 & 76,208 \\
\hline & STANDARD ERROR & 15,397 & 19,138 & 24,099 \\
\hline & ANOVA & & 0,001 & \\
\hline & POST HOC & T0-T1 0,004 & T1-T2 0,005 & T0-T2 $\mathbf{0 , 0 0 4}$ \\
\hline \multirow{5}{*}{ CONTROL GROUP } & AVERAGE & 57,60 & 57,70 & 57,30 \\
\hline & STANDARD DEVIATION & 36,265 & 36,022 & 38,480 \\
\hline & STANDARD ERROR & 11,468 & 11,391 & 12,168 \\
\hline & ANOVA & & 0,620 & \\
\hline & POST HOC & T0-T1 -..-- & T1-T2 -.-- & T0-T2 -..- \\
\hline
\end{tabular}


ments strength throughout all the follow ups but without any statistical significance. (tab.10)

\section{Conclusion}

Associating laser treatment and Grimaldi's Muscle
Shortening Manoeuvre (MSM) seems to be effective on muscle strength and motor control in patients affected by subtotal SCI compared to a control group. We must, however, further control our data on larger number of patients and with longer follow-ups.

Conference, Springer NY.

9: Anders J, (2009). The Potential of Light Therapy for Central Nervous System Injury and Disease. Photomedicine and Laser Surgery, 27(3), pp. 37980

10: Oda-Mochizuki N. (2007). Neuronal and cellular effects of low level laser: Basic and clinical research.

Nippon Laser Igakkaishi, 28, pp 57-57.

11: Fork R.L. (1971). Laser stimulation of nerve cells in aplysia. Science. 171, pp 907-908

12: Yoshimi Asagai (2007). Application of LLLT in patients with cerebral palsy of the adult tension athetosis

type. Nippon Laser Igakkaishi, 28, pp 74-76

13: Morselli M., Soragni O., Anselmi B.P. Very Low Energy Density Treatment by $\mathrm{CO}_{2}$ laser in sport injuries. Lasers in Surgery and Medicine, 5:150, 1985

14: Longo L, Tamburini A, Monti A, Cattaneo L, Sesti AG: Treatment with 904 and $10600 \mathrm{~nm}$ laser of acute lumbago: double blind control Laser I (3):1620, 1988

15: Longo L, Clementi F CO2 laser treatment of calcific metaplasias in P. Spinelli, M Dal Fante, R Marchesini ed. Photodynamic therapy and Biomedical lasers, Excerpta Medica, Internat. Congress Series 1011, Elsevier Publisher, Amsterdam, pp 186-190,1993

\section{[Acknowledgements]}

All procedures performed in studies involving human participants were in accordance with the ethical standards of the institutional and/or national research committee and with the 1964 Helsinki declaration and its later amendments or comparable ethical standards.

The authors declare that they have no conflict of interest. 